\title{
Computed tomography indicators of cerebral microperfusion improve long term after carotid stenting in symptomatic patients
}

\author{
Pawel J. Winklewski1,2,3凶, Mariusz Kaszubowski4, Grzegorz Halena5, Agnieszka Sabisz³, \\ Kamil Chwojnicki 6 , Jarosław Dzierżanowski7, Maciej Piskunowicz ${ }^{8}$, Natalia Kurhaluk9, \\ Edyta Szurowska ${ }^{3}$ and Arkadiusz Szarmach ${ }^{3}$
}

1Department of Human Physiology, Medical University of Gdansk, Gdańsk, Poland; 2Department of Clinical Anatomy and Physiology, Pomeranian University of Slupsk, Słupsk, Poland; ${ }^{32-n d ~ D e p a r t m e n t ~ o f ~ R a d i o l o g y, ~ M e d i c a l ~ U n i v e r s i t y ~ o f ~ G d a n s k, ~ G d a n ́ s k, ~ P o l a n d ; ~}{ }^{4}$ Department of Economic Sciences, Gdansk University of Technology, Gdańsk, Poland; ${ }^{5}$ Department of Cardiovascular Surgery, Medical University of Gdansk, Gdańsk, Poland; 'Department of Adults' Neurology, Medical University of Gdansk, Gdańsk, Poland; 'Department of Neurosurgery, Medical University of Gdańsk, Poland; ${ }^{81-s t ~ D e p a r t m e n t ~ o f ~ R a d i o l o g y, ~ M e d i c a l ~ U n i v e r s i t y ~ o f ~ G d a n s k, ~ G d a n ́ s k, ~ P o l a n d ; ~}{ }^{9}$ Department of Physiology, Pomeranian University of Slupsk, Słupsk, Poland

Objectives: We tested the hypothesis that computed tomography (CT) perfusion markers of cerebral microcirculation would improve 36 months after internal carotid artery stenting for symptomatic carotid stenosis while results obtained 6-8 weeks after the stenting procedure would yield a predictive value. Methods: We recruited consecutive eligible patients with $>70 \%$ symptomatic carotid stenosis with a complete circle of Willis and normal vertebral arteries to the observational cohort study. We detected changes in the cerebral blood flow (CBF), cerebral blood volume (CBV), mean transit time (MTT), time to peak (TTP) and permeability surface area-product (PS) before and after carotid stenting. We have also compared the absolute differences in the ipsilateral and contralateral CT perfusion markers before and after stenting. The search for regression models of "36 months after stenting" results was based on a stepwise analysis with bidirectional elimination method. Results: A total of 34 patients completed the 36 months follow-up (15 females, mean age of $69.68 \pm$ S.D. 7.61 years). At 36 months after stenting, the absolute values for CT perfusion markers had improved: CBF (ipsilateral: $+7.76 \%$, contralateral: $+0.95 \%$ ); CBV (ipsilateral: $+5.13 \%$, contralateral: $+3.00 \%$ ); MTT (ipsilateral: $-12.90 \%$; contralateral: $-5.63 \%$ ); TTP (ipsilateral: $-2.10 \%$, contralateral: $-4.73 \%$ ) and PS (ipsilateral: $-35.21 \%$, contralateral: $-35.45 \%)$. MTT assessed 6-8 weeks after stenting predicted the MTT value 36 months after stenting (ipsilateral: $\mathrm{R} 2=0.867$, contralateral $\mathrm{R} 2=0.688$ ). Conclusions: We have demonstrated improvements in CT perfusion markers of cerebral microcirculation health that persist for at least 3 years after carotid artery stenting in symptomatic patients. MTT assessed 6-8 weeks after stenting yields a predictive value.

Key words: carotid artery stenosis, mean transit time, permeability surface area-product, cerebral blood flow, computed tomography perfusion

Received: 20 March, 2019; revised: 21 March, 2019; accepted: 24 March, 2019; available on-line: 08 April, 2019

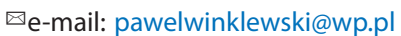

Acknowledgements of Financial Support: Pawel Jan Winklewski was supported by the Polish National Science Centre (NCN) grant number 2017/01/X/NZ5/00909

Abbreviations: $\mathrm{BBB}$, blood brain barrier; CTP, computed tomography perfusion; $\mathrm{CBV}$, cerebral blood volume; $\mathrm{CBF}$, cerebral blood flow; DSA, digital subtractive angiography; MTT, mean transit time; NECT, non-enhanced CT; NASCET, North American Symptomatic Carotid Endarterectomy Trial; ROls, Region of Interest; RICA, Right internal carotid artery; PS, permeability surface area-product; TIA, Transient ischemic Attacks; TTP, time to peak

\section{INTRODUCTION}

It has been recently postulated that it is not just the degree of internal carotid artery stenosis that adversely influences the cognitive aging but rather that the vascular stiffening provides a potential target for ameliorating the age-related cognitive decline. Consequently, augmented pulse pressure or carotid pulsatility were suggested to be more important in the development of white matter hyperintensities and declining cognitive function than the carotid artery stenosis itself (Aribisala et al., 2014; Singer et al., 2014; van Sloten et al., 2015; Wardlaw et al., 2017).

We have recently described a complex picture of a regional resting state perfusion variability in subjects with chronic carotid artery stenosis before the stenting procedure (Szarmach et al., 2018). Our study had shown a relatively well-balanced circulation, as measured by uniform regional response to an acetazolamide test, with low or very low cerebral blood flow (CBF) in these subjects (Szarmach et al., 2018). All of these findings taken together suggest that subjects with carotid artery stenosis represent a state of chronic cerebral hypoperfusion.

Animal models of chronic brain hypoperfusion, in turn, provide evidence that a decrease in the blood supply is associated with complex pathophysiological changes encompassing hypoxia, inflammation and oxidative stress (Kim et al., 2012; Duncombe et al., 2017). Furthermore, long-term hypoperfusion potentially accelerates the development of age-related ultrastructural aberrations of capillaries resulting in disruption of the blood brain barrier (BBB). BBB damage, in turn, is considered as a main initial pathogenic mechanism in the cerebral small vessel disease (Ding et al., 2017).

It becomes clear that improvement in outcomes for patients with carotid stenosis requires a better understanding of chronic changes in the brain macro and microcirculation. It can be crucial for better use of such procedures as carotid endarterectomy or stenting. Furthermore, it may open new perspectives in terms of such medical interventions as encouraging healthy life- 
style habits and appropriate use of medication (Abbott, 2016). Consequently, when assessing effects of the carotid stenting, a wider perspective should be taken into account. In particular, apart from the well-recognised beneficial effect of atherosclerotic plaque stabilisation and widely studied $\mathrm{CBF}$, other less recognized radiological markers encompassing the brain microcirculation and inflammatory status should be analysed. Furthermore, long term effects of carotid artery stenting are poorly understood. Computed tomography perfusion (CTP) provides an easy and fast way of obtaining colour-coded maps quantifying such perfusion parameters as $\mathrm{CBF}$, cerebral blood volume (CBV), mean transit time (MT'T), time to peak (TTP) and permeability surface area-product (PS).

CTP gives an opportunity to measure physiological parameters of microcirculation in the brain by fast acquisition of bolus injection of the contrast agent. CBF is expressed in millilitre per $100 \mathrm{~g}$ wet weight of the brain tissue per minute $(\mathrm{ml} / 100 \mathrm{~g} / \mathrm{min})$. This parameter provides information on the quantity of blood flowing across a particular region of the brain. CBV is calculated in millilitre per $100 \mathrm{~g}$ wet weight of the brain tissue $(\mathrm{ml} / 100 \mathrm{~g})$. This provides information on the amount of blood remaining in the microcirculation. MT'T reflects the time difference between the arterial inflow and the venous outflow. It is expressed in seconds (sec.). TTP reflects the time elapsing until the maximum concentration of contrast agent is reached within the ROI (sec.). PS measures the permeability of the BBB to contrast material (expressed in $\mathrm{ml} / \mathrm{min} / 100 \mathrm{ml}$ tissue) (Cuenod \& Balvay, 2013). In healthy subjects, the intact BBB is impermeable for large molecules, such as the iodinated contrast agent. In neoplasms, inflammatory/infectious states, ischaemia, and neurodegenerative diseases, the $\mathrm{BBB}$ is impaired, and the diffusion of fluid, blood or contrast molecules into the extravascular space is augmented (Jain et al., 2008; Topakian et al., 2010; Avsenik et al., 2015). PS was higher in the investigated sample when compared to the control subjects, indicating BBB impairment and enhanced permeability (Szarmach et al., 2017).

It is particularly tempting to use the combination of MTT and PS to assess the brain pathophysiology before and after carotid artery stenting. MT'T, defined as the average transit time of blood through a given brain region (measured in seconds), seems particularly sensitive to changes in the brain perfusion characteristics (Waaijer et al., 2007). PS, in turn, may provide a radiological marker of inflammatory states, ischaemia and neurodegenerative processes that typically compromise the BBB (Topakian et al., 2010; Taheri et al., 2011; Yang et al., 2011; Yang et al., 2015). In addition, BBB and PS taken together may be potentially considered as radiological markers of the cerebral small vessel disease (Cao et al., 2016; Arba et al., 2017). Consequently, we hypothesised that MTT and PS may provide useful predictive information with respect to the internal carotid artery stenting results 36 months post stenting procedure in patients with chronic carotid artery stenosis.

\section{MATERIALS AND METHODS}

Patient sample. Test power analysis was used prospectively to estimate the study sample size. Our own observations suggested values of mean and SD before stenting. A sample size consisting of 34 was based on calculations for those CT parameters assuming $\alpha=0.05$ and $1-\beta=0.9$.

The following inclusion criteria were defined:
1. Age $>18$ years.

2. Written consent to participate in the study.

3. Symptomatic stenosis of more than $70 \%$ within a single internal carotid artery (without vertebral and subclavian flow disturbances) were included in the study.

4. Complete circle of Willis and normal vertebral arteries confirmed by digital subtractive angiography (DSA).

Symptomatic carotid disease was defined as focal neurologic symptoms that were sudden in onset and referable to the appropriate carotid artery distribution (ipsilateral to significant carotid atherosclerotic pathology), including one or more transient ischemic attacks (TIA) or one or more minor (non-disabling) ischaemic strokes (IS; NASCET, 1991). The definition is contingent on the occurrence of carotid symptoms within the 6 previous months (NASCET, 1991; MRC, 1991). Diagnosis of IS was based on the WHO's definition: "clinical syndrome consisting of rapidly developing clinical signs of focal (or global in case of coma) disturbance of cerebral function lasting more than 24 hours or leading to death with no apparent cause other than a vascular origin". Hemorrhagic stroke was excluded by brain CT. If duration of symptoms was $<24$ hours, TIA was diagnosed (WHO Monica Project, 1988).

Degree of stenosis was diagnosed on the basis of a Doppler examination according to the North American Symptomatic Carotid Endarterectomy Trial (NASCET, 1991) criteria and was confirmed by DSA directly before the stent implantation. Carotid duplex ultrasound was at a clinical follow-up visits 1 month after treatment, 6 months and then annually after enrolment.

The following exclusion criteria were specified:

1. Significant $(>70 \%)$ tandem carotid stenosis.

2. Intracranial tumours, aneurysm, vessel malformations.

3. Post-stroke disability (modified Rankin score (mRs) $>1$ ), cognitive impairment (Mini-Mental State Examination $<24$ or The Lawton Instrumental Activities of Daily Living Scale $<3$ ).

4. Uncontrolled hyperthyroidism.

5. Hypersensitivity to iodine or history of adverse effects following the administration of contrast agents.

6. Stage II-V renal insufficiency were excluded from the study.

Between April 2010 and December 2014, initially a total of 107 patients were subjected to internal carotid artery stenting procedures at the Department of Cardiac and Vascular Surgery of the Medical University of Gdansk. 55 patients fulfilled the enrolment criteria. Consecutive eligible patients were recruited. Eight subjects did not agree to a control examination after 36 months, eight subjects had died and four subjects had changed their place of living. Finally, 34 subjects accomplished the study, (15 females (44.1\%) and 19 males (55.9\%); mean age of $69.68 \pm$ standard deviation (SD) 7.61 years). Risk factors and concomitant diseases in the studied sample are provided in Table 1 . We do not have detailed information regarding the medical treatments received by patients.

This study was carried out in accordance with the recommendations of the Declaration of Helsinki, with written informed consent from all subjects. The protocol was approved by the Independent Ethics Committee of the Medical University of Gdansk (NKBBN/383/2008).

Imaging protocol. To evaluate the cerebral blood supply in all subject patients, three CTP examinations were carried out: the first was performed 24 hours before the internal carotid artery stenting procedure, the second was performed 6-8 weeks afterwards, while the 
Table 1. Risk factors and concomitant diseases in the studied sample.

\begin{tabular}{|c|c|}
\hline Risk factors and concomitant diseases & $\mathrm{N}(\%)$ \\
\hline Total number of patients & 34 \\
\hline Age & $69.68 \pm$ SD 7.61 \\
\hline Women & $15(44.1 \%)$ \\
\hline Active smokers & $12(35.3)$ \\
\hline Arterial hypertension* & $28(82.4)$ \\
\hline Diabetes mellitus type $2^{* *}$ & $10(29.4)$ \\
\hline $\operatorname{COPD}^{* * * *}$ & $3(8.8)$ \\
\hline Transient ischemic attack (TIA) & $29(85.3)$ \\
\hline Ischemic stroke (IS) & $5(14.7)$ \\
\hline Coronary artery disease ${ }^{* * * *}$ & $22(64.7)$ \\
\hline Lipid disorders ${ }^{* * *}$ & $10(29.4)$ \\
\hline Myocardial infarction**** & $12(35.3)$ \\
\hline Chronic kidney disease ${ }^{* * * *}$ & $1(2.9)$ \\
\hline
\end{tabular}

COPD, chronic obstructive pulmonary disease; SD, standard deviation; IS and TIA, according to WHO definitions (WHO Monica Project, 1988); *history and antihypertensive treatment; ${ }^{* *}$ history or hypoglycemic treatment; ${ }^{* *}$ history or lipid lowering treatment; ${ }^{* * *}$ confirmed by hospital or out-patient documentation

third was 36 months ( \pm 4 months) post stent implantation.

Our CT perfusion technique has been previously described in detail (Szarmach et al., 2016; Szarmach et al., 2017; Szarmach et al., 2018). Briefly, all CT examinations were performed with the use of the same scanner (64-

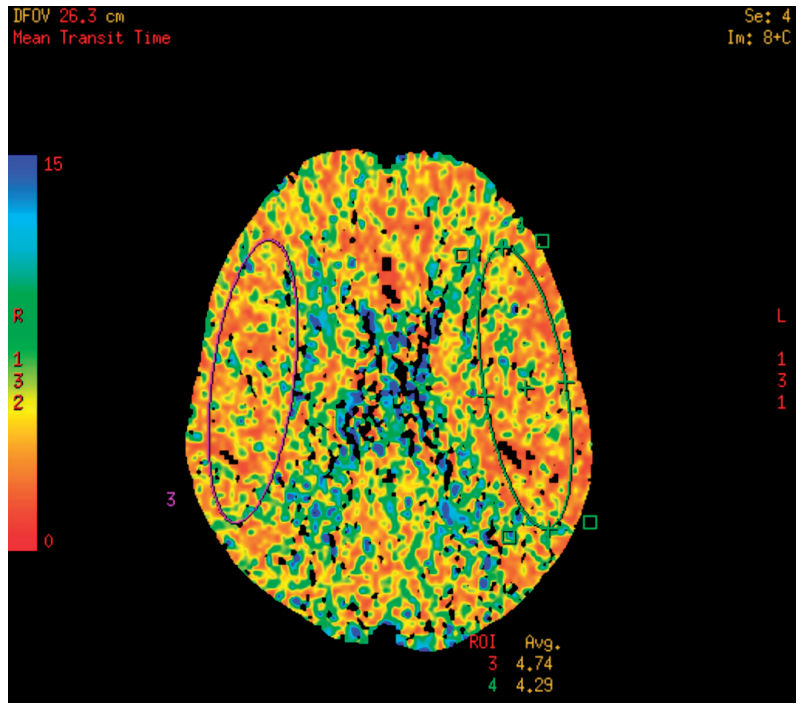

MDct Light Speed VCT XT, GE Healthcare Technologies, Wisconsin, USA).

The CT protocol consisted of non-enhanced CT (NECT) images that were obtained with such parameters as: $5-\mathrm{mm}$ contiguous axial sections from vertex to skull base, tube voltage and current $=140 \mathrm{kVp}, 335 \mathrm{mAs}, 0.9$ second rotation time, the number of images $=56$, total exposure time $=6.3 \mathrm{~s}$, and CDTIvol between 50 and 60 $\mathrm{mGy}$.

CTP studies were acquired during injection of $40 \mathrm{ml}$ of the contrast agent (Optiray 350 Mallinckrodt, St. Louis, Missouri, USA) with a flow rate of $4 \mathrm{ml} / \mathrm{s}$ followed by $40 \mathrm{ml}$ saline using an antecubital intravenous injection.

Perfusion imaging was obtained at eight levels (40 $\mathrm{mm}$ thick axial scans) with the following parameters: tube voltage $=80 \mathrm{kVp}$, current $=150 \mathrm{mAs}$, slice thickness $=5 \mathrm{~mm}$, rotation time $=1 / \mathrm{s}$, number of images per rotation $=8$, cine time between images $=0.5 \mathrm{~s}$, image matrix $=512 \times 512$, field-of-view $(\mathrm{FOV})=25 \mathrm{~cm}$, time interval between reconstructed images $=0.5 \mathrm{~s}$ and interval $=0 \mathrm{~mm}$. A total of 360 slices were obtained with a total scan time of 45 seconds. CDTIvol was approximately $390 \mathrm{mGy}$ per examination.

The first scan was set at the basal ganglia, above the level of the circle of Willis.

The arterial input function was chosen within the anterior cerebral artery. The venous output region was selected from the superior sagittal sinus.

Image post-processing. CT perfusion data were transferred to a post-processing workstation (AW 4 GE Healthcare Technologies, Wisconsin, USA) with a professional software package (CT Perfusion version 4 (v 4.3.1), GE Healthcare Technologies, Wisconsin, USA) to create colour maps of CBV, CBF, MT'T, TTP and PS.

All subjects were analysed using the same equipment and post-processing software, increasing the reliability of the obtained results.

Two, 10-year experienced neuroradiologists (blinded to side and time of operation) independently drew two standardised elliptical mirrored regions of interest (ROIs) manually. Each ROI (approximately $20 \mathrm{~cm}^{2}$ each) was determined at all of the analysed levels (Fig. 1a, b), over

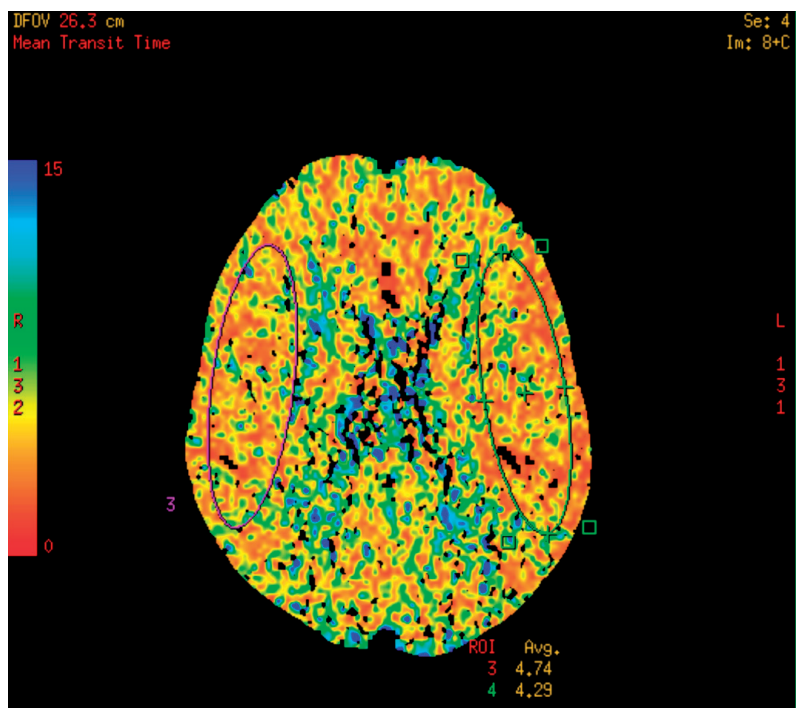

Figure 1. Mean Transit Time (MTT) CTP images in a patient with severe right internal carotid artery (RICA) stenosis.

Regions of interest (ROIs) placed on MCA (Middle Cerebral Artery) territories. Before (left) and 3 years after (right) carotid artery stenting. Decline in the average MTT after stenting was visible in both hemispheres. Colour scale corresponds to the different MTT values (blue, elongate; red, shortened). 
Table 2. Comparison of CTP values before stenting and 36 months post stenting.

\begin{tabular}{|c|c|c|c|c|c|}
\hline \multirow[t]{2}{*}{ Variable } & \multicolumn{5}{|c|}{$\begin{array}{c}\text { Parametric } t \text { Tests for dependent samples } \\
\text { Number of observation }=34 \\
\Gamma_{3} \text {, CTP parameter long after stenting; } \mathrm{CT}_{1}, \mathrm{CTP} \text { parameter before stenting }\end{array}$} \\
\hline & Side & Mean \pm SD (Median) & Change & $\mathrm{T}$ & $\mathrm{P}$ \\
\hline $\mathrm{MTT}_{1}$ & \multirow{2}{*}{ Ipsilateral } & $4.667 \pm 1.381(4.181)$ & \multirow{2}{*}{$-12.90 \%$} & \multirow{2}{*}{4.046} & \multirow{2}{*}{$<0.001$} \\
\hline $\mathrm{MTT}_{3}$ & & $4.065 \pm 0.855(3.825)$ & & & \\
\hline $\mathrm{MTT}_{1}$ & \multirow{2}{*}{ Contralateral } & $4.313 \pm 0.875(4.104)$ & \multirow{2}{*}{$-5.63 \%$} & \multirow{2}{*}{2.456} & \multirow{2}{*}{0.019} \\
\hline $\mathrm{MTT}_{3}$ & & $4.070 \pm 0.702(3.979)$ & & & \\
\hline $\mathrm{CBV}_{1}$ & \multirow{2}{*}{ Ipsilateral } & $1.735 \pm 0.288(1.739)$ & \multirow{2}{*}{$+5.13 \%$} & \multirow{2}{*}{-1.604} & \multirow{2}{*}{0.118} \\
\hline $\mathrm{CBV}_{3}$ & & $1.824 \pm 0.323(1.823)$ & & & \\
\hline $\mathrm{CBV}_{1}$ & \multirow{2}{*}{ Contralateral } & $1.769 \pm 0.307(1.706)$ & \multirow{2}{*}{$+3.00 \%$} & \multirow{2}{*}{-0.876} & \multirow{2}{*}{0.388} \\
\hline $\mathrm{CBV}_{3}$ & & $1.822 \pm 0.283(1.810)$ & & & \\
\hline $\mathrm{CBF}_{1}$ & \multirow{2}{*}{ Ipsilateral } & $37.412 \pm 9.129(37.866)$ & \multirow{2}{*}{$+7.76 \%$} & \multirow{2}{*}{-2.341} & \multirow{2}{*}{0.025} \\
\hline $\mathrm{CBF}_{3}$ & & $40.315 \pm 7.822(42.102)$ & & & \\
\hline $\mathrm{CBF}_{1}$ & \multirow{2}{*}{ Contralateral } & $39.002 \pm 6.630(38.178)$ & \multirow{2}{*}{$+0.95 \%$} & \multirow{2}{*}{-0.295} & \multirow{2}{*}{0.770} \\
\hline $\mathrm{CBF}_{3}$ & & $39.374 \pm 5.148(39.238)$ & & & \\
\hline$\Pi_{1} P_{1}$ & \multirow{2}{*}{ Ipsilateral } & $25.762 \pm 3.275(25.539)$ & \multirow{2}{*}{$-2.10 \%$} & \multirow{2}{*}{0.537} & \multirow{2}{*}{0.595} \\
\hline$\pi P_{3}$ & & $25.220 \pm 7.025(24.577)$ & & & \\
\hline $\mathrm{TTP}_{1}$ & Contralateral & $25.527 \pm 3.257(25.199)$ & & 4246 & $<0001$ \\
\hline $\mathrm{TTP}_{3}$ & Cutriaraterai & $24.319 \pm 3.419(24.611)$ & 4.1570 & 4.240 & $<0.001$ \\
\hline $\mathrm{PS}_{1}$ & & $1.542 \pm 0.795(1.369)$ & & 4462 & $<0 \cap 01$ \\
\hline $\mathrm{PS}_{3}$ & pstraterar & $0.999 \pm 0.268(1.030)$ & $-50.21 \%$ & 4.402 & 8.001 \\
\hline $\mathrm{PS}_{1}$ & Contralateral & $1.478 \pm 0.781(1.378)$ & $3545 \%$ & 4.007 & $<0.001$ \\
\hline $\mathrm{PS}_{3}$ & Cumbrateral & $0.951 \pm 0.320(0.943)$ & (5.457 & 4.001 & $<0.001$ \\
\hline $\mathrm{rMTT}_{1}$ & & $1.094 \pm 0.273(1.060)$ & $-7.59 \%$ & 1.439 & 0.155 \\
\hline $\mathrm{rMTT}_{3}$ & & $1.011 \pm 0.195(0.988)$ & & & \\
\hline $\mathrm{rCBV}_{1}$ & & $0.961 \pm 0.192(0.962)$ & $+6.56 \%$ & -1.520 & 0.134 \\
\hline $\mathrm{rCBV}_{3}$ & & $1.024 \pm 0.150(1.017)$ & & & \\
\hline $\mathrm{rCBF}_{1}$ & & $0.990 \pm 0.088(1.006)$ & & -0581 & 0563 \\
\hline $\mathrm{rCBF}_{3}$ & & $1.001 \pm 0.067(1.001)$ & & -0.501 & 0.505 \\
\hline $\mathrm{rTTP}_{1}$ & & $1.010 \pm 0.029(1.006)$ & & -0 658 & 0515 \\
\hline $\mathrm{rTTP}_{3}$ & & $1.031 \pm 0.189(0.997)$ & & -0.030 & 0.015 \\
\hline $\mathrm{rPS}_{1}$ & & $1.087 \pm 0.335(1.057)$ & & -0.120 & 0.905 \\
\hline $\mathrm{rPS}_{3}$ & & $1.095 \pm 0.239(1.061)$ & & -0.120 & 0.905 \\
\hline
\end{tabular}

the cortical grey matter centred $20 \mathrm{~mm}$ from the margin of the brain. The large vessels and bones were automatically excluded via the brain perfusion software.

Our perfusion application offers two different models of evaluation: the "neuro brain stroke" and the "neuro brain tumour". The first mode applies the maximal slope method (Fiorella et al., 2004; Szarmach et al., 2016; Szarmach et al., 2017) for measurement of CBF, CBV, MTT or TTP, while the second one calculates microvascular permeability (PS) and the fractional blood volume based on the Johnson and Wilson model (St Lawrence \& Lee, 1998a; St Lawrence \& Lee, 1998b).

The absolute values of CT perfusion parameters (CBF, CBV, MTT, TTP, and PS) of one hemisphere in the region of the middle cerebral artery distribution and contralateral mirroring areas in functional maps were calculated.

Statistical analysis. To compare results before and after stenting, differences in the absolute CTP values
(CBF, CBV, MTT, TTP and PS) and side to side relative values (rCBF, rCBV, rMTT, rTTP, rPS-obtained as the ratio of appropriate values from ipsilateral side to contralateral side to stenosis) were analysed.

All raw data were presented with their descriptive statistics, such as the number, mean, SD and percentage change. Materials were collected from all individual slices, measured by two independent specialists and finally averaged per patient. Differences between the mean values were examined by parametric Welch's t-test (symbol t).

The search for regression models of " 36 months after stenting" results were based on a stepwise analysis with bidirectional elimination method. The set of possible explanatory variables were: "before stenting", “just after stenting" outcomes and also the degree of stenosis information (70-89\%, low; 90-99\%, high). The level of significance was set at $\alpha=0.05$. All calculated $\mathrm{p}$-values 
Table 3. Results of linear one-dimensional regression models for CTP parameters.

\begin{tabular}{|c|c|c|c|c|c|c|c|c|}
\hline \multirow{3}{*}{$\mathrm{CT}_{3}$} & \multicolumn{8}{|c|}{$\begin{array}{c}\text { Linear regression model for CTP parameters } \\
\qquad T_{3}=a_{1}+a_{1} x \mathrm{CT}_{2} \\
\mathrm{CT}_{3} \text {, CTP parameter } 36 \text { months after stenting; } \mathrm{CT}_{2}, \mathrm{CTP} \text { parameter 6-8 weeks after stenting }\end{array}$} \\
\hline & \multirow{2}{*}{ Side } & \multicolumn{4}{|c|}{ Model } & \multirow{2}{*}{$\mathrm{F}$ ( $p$-value $)$} & \multirow{2}{*}{ SE } & \multirow{2}{*}{$\mathrm{R}^{2}$} \\
\hline & & \multicolumn{2}{|c|}{ Coefficients } & Error & t ( $p$-value) & & & \\
\hline \multirow{4}{*}{$\mathrm{MTT}_{3}$} & \multirow{2}{*}{ Ipsilateral } & $a_{1}$ & 1.100 & 0.209 & $5.265(<0.001)$ & \multirow{2}{*}{$\begin{array}{l}215.39 \\
(<0.001)\end{array}$} & \multirow{2}{*}{0.312} & \multirow{2}{*}{0.867} \\
\hline & & $a_{2}$ & 0.752 & 0.051 & $14.676(<0.001)$ & & & \\
\hline & \multirow{2}{*}{ Contralateral } & $a_{1}$ & 1.265 & 0.334 & $3.792(0.001)$ & \multirow{2}{*}{$\begin{array}{l}73.69 \\
(<0.001)\end{array}$} & \multirow{2}{*}{0.392} & \multirow{2}{*}{0.688} \\
\hline & & $a_{2}$ & 0.752 & 0.088 & $8.584(<0.001)$ & & & \\
\hline \multirow{4}{*}{$\mathrm{CBV}_{3}$} & \multirow{2}{*}{ Ipsilateral } & $a_{1}$ & 0.629 & 0.241 & $2.611(0.014)$ & \multirow{2}{*}{$\begin{array}{l}25.42 \\
(<0.001)\end{array}$} & \multirow{2}{*}{0.245} & \multirow{2}{*}{0.425} \\
\hline & & $\mathrm{a}_{2}$ & 0.588 & 0.117 & $5.042(<0.001)$ & & & \\
\hline & \multirow{2}{*}{ Contralateral } & $a_{1}$ & 0.785 & 0.225 & $3.492(0.001)$ & \multirow{2}{*}{$\begin{array}{l}21.92 \\
(<0.001)\end{array}$} & \multirow{2}{*}{0.221} & \multirow{2}{*}{0.388} \\
\hline & & $a_{2}$ & 0.512 & 0.109 & $4.681(<0.001)$ & & & \\
\hline \multirow{4}{*}{$\mathrm{CBF}_{3}$} & \multirow{2}{*}{ Ipsilateral } & $\mathrm{a}_{1}$ & 11.426 & 3.833 & $2.981(0.005)$ & \multirow{2}{*}{$\begin{array}{l}59.42 \\
(<0.001)\end{array}$} & \multirow{2}{*}{4.700} & \multirow{2}{*}{0.639} \\
\hline & & $a_{2}$ & 0.639 & 0.083 & $7.708(<0.001)$ & & & \\
\hline & \multirow{2}{*}{ Contralateral } & $a_{1}$ & 22.920 & 3.447 & $6.649(<0.001)$ & \multirow{2}{*}{$\begin{array}{l}23.71 \\
(<0.001)\end{array}$} & 2062 & ח \\
\hline & & $a_{2}$ & 0.353 & 0.072 & $4.869(<0.001)$ & & 3.902 & 0.408 \\
\hline & Incilatoral & $a_{1}$ & -8.051 & 7.260 & $-1.109(0.276)$ & 21.37 & 5524 & 387 \\
\hline & ipsiacteid & $a_{2}$ & 1.405 & 0.304 & $4.622(<0.001)$ & $(<0.001)$ & $3.5<4$ & 0.382 \\
\hline $11 r_{3}$ & Contralateral & $a_{1}$ & 0.972 & 1.864 & $0.521(0.606)$ & 159.53 & 1419 & 0828 \\
\hline & & $\mathrm{a}_{2}$ & 0.994 & 0.079 & $12.630(<0.001)$ & $(<0.001)$ & & \\
\hline & Insilateral & $a_{1}$ & 0.580 & 0.111 & $5.224(<0.001)$ & 16.11 & 0.222 & 0314 \\
\hline PS & & $\mathrm{a}_{2}$ & 0.512 & 0.128 & $4.013(<0.001)$ & $(<0.001)$ & 0.222 & 0.314 \\
\hline $\mathrm{PJ}_{3}$ & Contralateral & $a_{1}$ & 0.426 & 0.119 & $3.589(0.001)$ & 22.49 & 0249 & 394 \\
\hline & & $a_{2}$ & 0.652 & 0.137 & $4.742(<0.001)$ & $(<0.001)$ & 0.249 & 0.394 \\
\hline
\end{tabular}

were for two-tailed tests. Full model description is provided in the Supplement. All raw data were analysed using the statistical software Statistica 13.1 (StatSoft, Tulsa, OK, USA).

\section{RESULTS}

Absolute $\mathrm{CBF}$ (ipsilateral: $+7.76 \%$, contralateral: $+0.95 \%)$; CBV (ipsilateral: $+5.13 \%$, contralateral: $+3.00 \%$ ); MTT (ipsilateral: $-12.90 \%$; contralateral: $-5.63 \%$ ); TTP (ipsilateral: $-2.10 \%$, contralateral: $-4.73 \%$ ) and PS (ipsilateral: $-35.21 \%$, contralateral: $-35.45 \%$ ) values had improved 36 months after carotid artery stenting (Table 2). We did not observe significant changes in the side to side relative values of the reported CT parameters (Table 2).

Comparison of CTP values before stenting and 6-8 weeks after stenting has been already published (Szarmach et al., 2014). The results are provided as Supplemental Table 1 at www.actabp.pl.

MT'T and PS outcomes 6-8 weeks after stenting ( $\mathrm{Ta}$ ble 3) predicted MTT and PS results 36 months after stenting for both, the ipsilateral and contralateral side. The higher the $\mathrm{R}^{2}$ value is, the stronger is the predictive value. The best prognostic value (in terms of coefficient $\mathrm{R}^{2}$ determination) had the models for MT'T parameters: $\mathrm{R}^{2}=0.867$ and $\mathrm{R}^{2}=0.688$ for the ipsilateral and contralateral side, respectively (Fig. 2 and Fig. 3). Consequently, in the case of MT'T parameters and for both hemispheres, we may expect that the higher the values after stenting, the higher the values over time. To be precise, a unit higher just after stenting, results in a 0.75 increment in the long term. In another words, in the next 4 years after stenting, MT'T is losing about $25 \%$ of its increase. PS outcomes 6-8 weeks after stenting yielded weaker prognostic value than MTT, with $\mathrm{R}^{2}=0.314$ for ipsilateral side and $\mathrm{R}^{2}=0.394$ for contralateral side ( $\mathrm{Ta}$ ble 3). Other CTP parameters (CBF, CBV, T'TP) did not provide any prognostic values.

At 36 months, two patients $(5.9 \%)$ who underwent the carotid artery stenting had restenosis. The degree

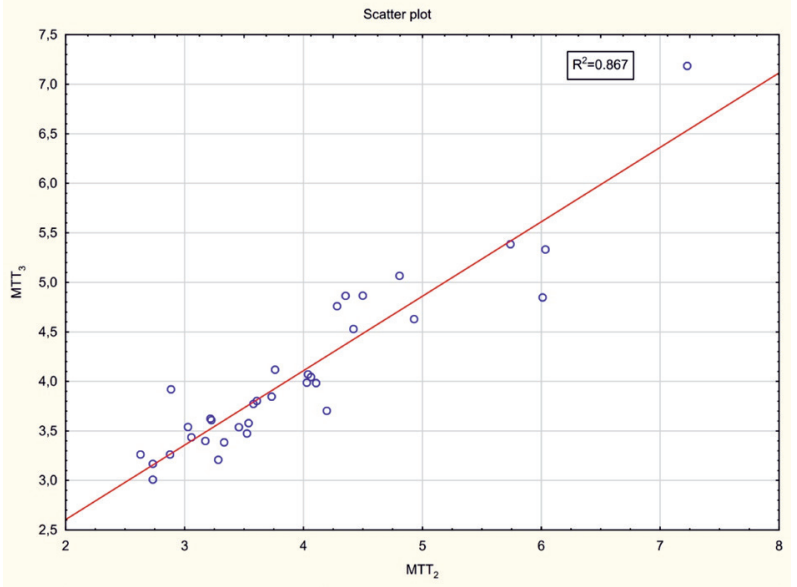

Figure 2. Scatter plot of MTT 36 months after stenting $\left(\mathrm{MTT}_{3}\right)$ vs. just after stenting for the ipsilateral side (MTT ${ }_{2}$ ). 


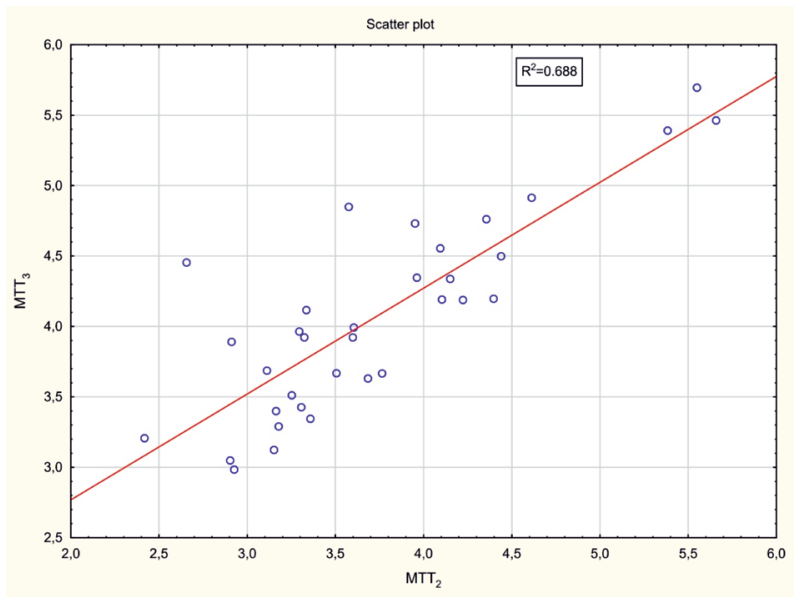

Figure 3. Scatter plot of MTT 36 months after stenting $\left(\mathrm{MTT}_{3}\right)$ vs. just after stenting for the contralateral side $\left(\mathrm{MTT}_{2}\right)$.

of stenosis immediately after 34 stents was below 15\% and in the two patients with restenosis, the stenosis at 36 months had progressed to $60-69 \%$ and $70-79 \%$, respectively (Supplemental Table 2 and 3 at www.actabp. $\mathrm{pl}$ ). In the remaining patients, stenosis was below $50 \%$. None of the patients had a stroke, myocardial infarction or died within 30 days of carotid stenting. None of the investigated patients had a stroke, TIA or myocardial infarction during 36 months post stenting.

\section{DISCUSSION}

There are two main findings of the study presented here: 1) CBF, CBV, MT'T, T'TP and PS improve 36 months after carotid artery stenting, 2) MTT and PS assessed 6-8 weeks after stenting predict the MTT and PS values 36 months post stenting.

Strong interdependence between severity of microcirculation impairment and the time-based perfusion parameters has been recently reported. In particular, MT'T appears to show a good association with the cerebral small vessel disease (Cao et al., 2016; Arba et al., 2017). There is actually a good pathophysiological reasoning explaining such interdependence. Leukoaraiosis, the radiological marker of cerebral small vessel disease, is linked to arteriolar tortuosity and thickening of the walls of periventricular veins and venules (Brown et al., 2002). Such changes in the shape and elastic properties of small vessels are very likely to affect the blood flow and, in turn, the average transit time of blood through an affected brain region. Moreover, chronic hypoxia and prolonged inflammatory status evoke the platelet activation and increase the pro-coagulative status (Oberheiden et al., 2010), which may further slowdown the blood flow velocity.

Our study demonstrates for the first time the predictive role of MTT in subjects undergoing carotid artery stenosis stenting. Consequently, lack of improvement in the MT'T parameter shortly after stenting procedure may potentially indicate a higher risk of developing the ischemic stroke or cognitive deterioration. Further studies are needed to establish a link between improvement in a radiological surrogate marker, such as MTT, and functional benefits for patients.

BBB impairment is another typical feature of the small vessel disease (Hassan et al., 2003; Wardlaw et al., 2009). Obviously, BBB dysfunction provides a pathophysiologi- cal substrate for improper neurovascular unit activity and general dysregulation of microcirculatory responses to changes in the metabolic demand of neurons (Hassan et al., 2003). Consequently, carotid artery stenting effects are not only limited to $\mathrm{CBF}$ improvement but also encompassed in a wide range of modifications to the ischaemic status of the brain. This study confirms our earlier results demonstrating that the carotid artery stenting and subsequent reperfusion diminish the BBB permeability (Szarmach et al., 2017). In addition, we show that it has a long term effect.

Quite surprisingly, PS, the radiological marker of $\mathrm{BBB}$ permeability, provided a weaker predictive value than MTT. BBB impairment is a multifactorial process consisting of several pathomechanisms, which actually may decrease its predictive value. Alternatively, the total scan time used in our study was $45 \mathrm{~s}$, while typically for measurement of PS, a longer acquisition time is recommended to avoid overestimation. For the firstpass CTP data, it is advised to obtain acquisition for at least $90 \mathrm{~s}$ and combine it with delay correction for 90 s CTP acquisition. The data available for the Patlak model suggest that shorter acquisitions may result in BBB permeability overestimation (Dankbaar et al., 2008; Hom et al., 2009). Consequently, the reported PS values may be overestimated. However, even if the BBB values are overestimated, the same procedure was adopted before and after stenting. Therefore, the relative changes remain valid.

Several authors had reported CBF and MT'T improvements in the early postinterventional phase (ranging from one day to a few weeks) after either carotid endarterectomy or stenting (Niesen et al., 2004; Gaudiello et al., 2008; Tavares et al., 2010; Ding et al., 2016; Szarmach et al., 2017). In turn, CBV assessed shortly (from one day to a few weeks) after the mentioned procedures either did not change (Matsubara et al., 2009; Tavares et al., 2010) or had increased (Kawai et al., 2014; Piñero et al., 2014; Ding et al., 2016; Szarmach et al., 2017). Only Trojanowska and others (Trojanowska et al., 2006) reported the perfusion parameter improvement in both hemispheres (CBF increase, MT'T and CBV decline) that persisted 6 months after carotid artery stenting. To the best of our knowledge, our study provides for the first time evidence that the beneficial effect is much longer and may last over 3 years. Quite interestingly, CBF longterm beneficial effect is limited to the ipsilateral side of stenting. CBV is not affected in both hemispheres. Thus, the MTT and PS decline that is visible in both, ipsilateral and contralateral sides, may suggest that stenosis present at the ipsilateral side before the carotid artery stenting affected both brain hemispheres, in terms of microcirculatory and inflammatory impairment. Consequently, by combining MT'T and PS, we were able to propose that carotid artery stenting may have a profound effect on the time course of cerebral small vessel disease in both hemispheres.

Several authors suggest that relative perfusion parameters (the symptomatic hemisphere-to-asymptomatic hemisphere $\mathrm{CBF}, \mathrm{CBV}$ and MTT ratios) may represent an early and sensitive parameter for the detection of perfusion changes (Wilkinson et al., 2003; Duan et al., 2012; Merckel et al., 2012). In the Wilkinson and others (Wilkinson et al., 2003) and Duan and others (Duan et al., 2012) studies, the relative CBF had increased and MTT had diminished, while the relative CBV did not change immediately (one day) after revascularisation. In the Merckel and others (Merckel et al., 2012) study, the 
relative $\mathrm{CBF}$ and $\mathrm{CBV}$ had augmented, while MTT had declined one day after procedure. In our study, we did not observe changes in the relative CBF, CBV, MTT, T'TP and PS. Our study sample consisted of patients with complete circle of Willis and normal vertebral arteries, while the $\mathrm{CBF}$ and $\mathrm{CBV}$ before stenting were low, suggesting a relatively well balanced collateral circulation (Szarmach et al., 2017). Consequently, stenting at the ipsilateral side limited the need for collateral supply, also improving circulation in the contralateral hemisphere. Taken together, it is not surprising that our relative $\mathrm{CBF}, \mathrm{CBV}$, MTT, TTP and PS indices did not change.

In-stent restenosis occurs more frequently, and the risks for ipsilateral ischaemic stroke and brain microinfarcts are higher after stenting than after endarterectomy (Bonati et al., 2009; Arquizan et al., 2011; Lal et al., 2012). Nevertheless, in the 2010-2014 years, when the study was conducted, internal carotid artery stenting was a frequently used procedure at our university hospital. CTP and Doppler ultrasound were a standard method of choice for perfusion and stenosis assessment in these patients. Therefore, frequency of microbleeds, micro ischemic strokes and functional status were not assessed. Such assessments, with the use of diffusion weighted (DWI) and blood-oxygenation level-dependent (BOLD) magnetic resonance imaging are currently under way. Actually, the aim of this study was not to compare carotid stenting versus endarterectomy, but to demonstrate that reperfusion benefits are not limited to $\mathrm{CBF}$, and also encompass improvement in microcirculation and BBB integrity. In our study sample, two subjects suffered from restenosis $(5.9 \%)$ during 36 months post stenting. Thus, the percentage was slightly lower when compared to restenosis frequency reported by other authors (Arquizan et al., 2011; Lal et al., 2012).

The main disadvantage of CTP is related to concerns associated with a high radiation dose. In our study, conventional angiography was anyway used to confirm the degree of stenosis. There are several advantages of CTP, like an easy and fast way acquisition of perfusionrelated parameters and a wide availability. In terms of MTT, CTP provides comparable data with magnetic resonance imaging (MRI). Ultra-low-dose virtual CTP enhanced by computed tomography angiography seems to be under development (Tong et al., 2014). Finally, the combination of computed tomography angiography with CTP, MTT and PS parameters may open a new era in human brain pathophysiology research.

To conclude, we have demonstrated that the advantages of carotid artery stenting are not limited to the CBF improvement. On the contrary, alleviation of hypoperfusion most likely modifies a wide number of parameters typical for prolonged ischaemia and related oxidative stress and inflammation. MT'T measured 6-8 weeks after stenting provides an important predictive value with respect to MTT 36 months post stenting, suggesting a persistent improvement in the brain microcirculation. Diminished PS values may suggest a decline in the overall oxidative and inflammatory status that is maintained in both hemispheres for over 3 years after stenting. Further studies are required to validate our findings and determine their significance with respect to functional benefits for patients, such as improved cognition or stroke prevention.

\section{Conflicts of Interest}

The authors declare no conflict of interest.

\section{Authorship}

PJW and ASz contributed conception and design of the study; $\mathrm{AS}_{\mathrm{z}}$ and MK organized the database; MK performed the statistical analysis; PJW wrote the first draft of the manuscript; MK, GH, AS, KCh, MP, NK, ES, ASz wrote sections of the manuscript. All authors contributed to manuscript revision, had read and approved the submitted version.

\section{REFERENCES}

Abbott A (2016) Critical issues that need to be addressed to improve outcomes for patients with carotid stenosis. Angiology 67: 420-426. https://doi.org/10.1177/0003319716631266

Arba F, Mair G, Carpenter T, Sakka E, Sandercock PAG, Lindley RI, Inzitari D, Wardlaw JM; IST-3 Trial Collaborators (2017) Cerebral white matter hypoperfusion increases with small-vessel disease burden. data from the third international stroke trial. I Stroke Cerebrovasc Dis 26: 1506-1513. https://doi.org/10.1016/j.jstrokecerebrovasdis.2017.03.002

Aribisala BS, Morris Z, Eadie E, Thomas A, Gow A, Valdés Hernández MC, Royle NA, Bastin ME, Starr J, Deary IJ, Wardlaw JM (2014) Blood pressure, internal carotid artery flow parameters, and age-related white matter hyperintensities. Hypertension 63: 1011-1018. https://doi.org/10.1161/HYPERTENSIONAHA.113.02735

Arquizan C, Trinquart L, Touboul PJ, Long A, Feasson S, Terriat B, Gobin-Metteil MP, Guidolin B, Cohen S, Mas JL; EVA-3S Investigators (2011) Restenosis is more frequent after carotid stenting than after endarterectomy: the EVA-3S study. Stroke 42: 1015-1020. https://doi.org/10.1161/STROKEAHA.110.589309

Avsenik J, Bisdas S, Popovic KS (2015) Blood-brain barrier permeability imaging using perfusion computed tomography. Radiol Oncol 49: 107-114. https://doi.org/10.2478/raon-2014-0029

Bonati LH, Ederle J, McCabe DJ, Dobson J, Featherstone RL, Gaines PA, Beard JD, Venables GS, Markus HS, Clifton A, Sandercock P, Brown MM; CAVATAS Investigators (2009) Long-term risk of carotid restenosis in patients randomly assigned to endovascular treatment or endarterectomy in the Carotid and Vertebral Artery Transluminal Angioplasty Study (CAVATAS): long-term follow-up of a randomised trial. Lancet Neurol 8: 908-917. https://doi.org/10.1016/ S1474-4422(09)70227-3

Brown WR, Moody DM, Challa VR, Thore CR, Anstrom JA (2002) Venous collagenosis and arteriolar tortuosity in leukoaraiosis. $J \mathrm{Neu}$ rol Sci 203-204: 159-163.

Cao W, Yassi N, Sharma G, Yan B, Desmond PM, Davis SM, Campbell BC (2016) Diagnosing acute lacunar infarction using CT perfusion. J Clin Neurosci 29: 70-72.

Cuenod CA, Balvay D (2013) Perfusion and vascular permeability: basic concepts and measurement in DCE-CT and DCE-MRI. Diagn Interv Imaging 94: 1187-1204. https://doi.org/10.1016/j.diii.2013.10.010

Dankbaar JW, Hom J, Schneider T, Cheng SC, Lau BC, van der Schaaf I, Virmani S, Pohlman S, Dillon WP, Wintermark M (2008) Dynamic perfusion CT assessment of the blood-brain barrier permeability: first pass versus delayed acquisition. Am J Neuroradiol 29: 1671-1676. https://doi.org/10.3174/ajnr.A1203

Ding L, Hong Y, Peng B (2017) Association between large artery atherosclerosis and cerebral microbleeds: a systematic review and meta-analysis. Stroke V asc Neurol 2: 7-14. https://doi.org/10.1136/ svn-2016-000049

Duan Y, Li G, Yang Y, Li J, Huang H, Wang H, Xu F, Chen W (2012) Changes in cerebral hemodynamics after carotid stenting of symptomatic carotid artery. Eur J Radiol 81: 744-748. https://doi. org/10.1016/j.ejrad.2011.01.042

Duncombe J, Kitamura A, Hase Y, Ihara M, Kalaria RN, Horsburgh K (2017) Chronic cerebral hypoperfusion: a key mechanism leading to vascular cognitive impairment and dementia. Closing the translational gap between rodent models and human vascular cognitive impairment and dementia. Clin Sci 131: 2451-2468. https://doi. org/10.1042/CS20160727

Fiorella D, Heiserman J, Prenger E, Partovi S (2004) Assessment of the reproducibility of postprocessing dynamic CT perfusion data. AJNR Am J Neuroradiol 25: 97-107.

Hassan A, Hunt BJ, O'Sullivan M, Parmar K, Bamford JM, Briley D, Brown MM, Thomas DJ, Markus HS (2003) Markers of endothelial dysfunction in lacunar infarction and ischaemic leukoaraiosis. Brain 126: $424-432$.

Gaudiello F, Colangelo V, Bolacchi F, Melis M, Gandini R, Garaci FG, Cozzolino V, Floris R, Simonetti G (2008) Sixty-four-section CT cerebral perfusion evaluation in patients with carotid artery stenosis before and after stenting with a cerebral protection device. $A m \mathrm{~J}$ Neuroradiol 29: 919-923. https://doi.org/10.3174/ajnr.A0945 
Hom J, Dankbaar JW, Schneider T, Cheng SC, Bredno J, Wintermark M (2009) Optimal duration of acquisition for dynamic perfusion CT assessment of blood-brain barrier permeability using the Patlak model. Am J Neuroradiol 30: 1366-137. https://doi.org/10.3174/ ajnr.A1592

Jain R, Ellika SK, Scarpace L, Schultz LR, Rock JP, Gutierrez J, Patel SC, Ewing J, Mikkelsen T (2008) Quantitative estimation of permeability surface-area product in astroglial brain tumors using perfusion CT and correlation with histopathologic grade. Am J Neuroradiol 29: 694-700. https://doi.org/10.3174/ajnr.A0899

Kawai N, Hatakeyama T, Okauchi M, Kawanishi M, Shindo A, Kudomi N, Yamamoto Y, Nishiyama Y, Tamiya, T (2014) Cerebral blood flow and oxygen metabolism measurements using positron emission tomography on the first day after carotid artery stenting. $J$ Stroke Cerebrovasc Dis 23: e55-e64. https://doi.org/10.1016/j.jstrokecerebrovasdis.2013.08.012

Kim HA, Miller AA, Drummond GR, Thrift AG, Arumugam TV, Phan TG, Srikanth VK, Sobey CG (2012) Vascular cognitive impairment and Alzheimer's disease: role of cerebral hypoperfusion and oxidative stress. Naunyn Schmiedebergs Arch Pharmacol 385: 953959. https://doi.org/10.1007/s00210-012-0790-7

Lal BK, Beach KW, Roubin GS, Lutsep HL, Moore WS, Malas MB, Chiu D, Gonzales NR, Burke JL, Rinaldi M, Elmore JR, Weaver FA, Narins CR, Foster M, Hodgson KJ, Shepard AD, Meschia JF, Bergelin RO, Voeks JH, Howard G, Brott TG; CREST Investigators (2012) Restenosis after carotid artery stenting and endarterectomy: a secondary analysis of CREST, a randomised controlled trial. Lancet Neurol 11: 755-763. https://doi.org/10.1016/S14744422(12)70159-X

Matsubara S, Moroi J, Suzuki A, Sasaki M, Nagata K, Kanno I, Miura S (2009) Analysis of cerebral perfusion and metabolism assessed with positron emission tomography before and after carotid artery stenting. J Neurosurg 111: 28-36. https://doi.org/10.3171/2008.09.17663

Merckel LG, Van der Heijden J, Jongen LM, van Es HW, Prokop M, Waaijer A (2012) Effect of stenting on cerebral CT perfusion in symptomatic and asymptomatic patients with carotid artery stenosis. AJNR Am J Neuroradiol 33: 280-285. https://doi.org/10.3174/ajnr. A 2757

European Carotid Surgery Trialists' Collaborative Group (1991) MRC European Carotid Surgery Trial: interim results for symptomatic patients with severe $(70-99 \%)$ or with mild $(0-29 \%)$ carotid stenosis. Lancet 337: 1235

Niesen WD, Rosenkranz M, Eckert B, Meissner M, Weiller C, Sliwka, U (2004) Hemodynamic changes of the cerebral circulation after stent-protected carotid angioplasty. Am J Neuroradiol 25: 1162-1167.

North American Symptomatic Carotid Endarterectomy Trial (NASCET) Collaborators (1991) Beneficial effect of carotid endarterectomy in symptomatic patients with high-grade carotid stenosis. New Engl J Med 325: 445-453

Oberheiden T, Blahak C, Nguyen XD, Fatar M, Elmas E, Morper N, Dempfle CE, Bäzner H, Hennerici M, Borggrefe M, Kälsch T (2010) Activation of platelets and cellular coagulation in cerebral small-vessel disease. Blood Coagul Fibrinolysis 21: 729-735. https:// doi.org/10.1097/MBC.0b013e328340147c

Piñero P, González A, Moniche F, Martínez E, Cayuela A, GonzálezMarcos JR, Mayol A, Gil-Peralta A (2014) Progressive changes in cerebral perfusion after carotid stenting: A dynamic susceptibility contrast perfusion weighted imaging study. J Neurointerv Surg 6: 527532. https://doi.org/10.1136/neurintsurg-2013-010859

Singer J, Trollor JN, Baune BT, Sachdev PS, Smith E (2014) Arterial stiffness, the brain and cognition: a systematic review. Ageing Res Rev 15: 16-27. https://doi.org/10.1016/j.arr.2014.02.002

St Lawrence KS, Lee TY (1998a) An adiabatic approximation to the tissue homogeneity model for water exchange in the brain: I. Theoretical derivation. J Cereb Blood Flow Metab 18: 1365-1377

St Lawrence KS, Lee TY (1998b) An adiabatic approximation to the tissue homogeneity model for water exchange in the brain: II. Experimental validation. J Cereb Blood Flow Metab 18: 1378-1385

Szarmach A, Halena G, Kaszubowski M, Piskunowicz M, Szurowska E, Frydrychowski AF, Winklewski PJ (2016) Perfusion computed tomography: $4 \mathrm{~cm}$ versus $8 \mathrm{~cm}$ coverage size in subjects with chronic carotid artery stenosis. Br J Radiol 89: 20150949. https://doi. org/10.1259/bjr.20150949

Szarmach A, Halena G, Kaszubowski M, Piskunowicz M, Studniarek M, Lass P, Szurowska E, Winklewski PJ (2017) Carotid artery stenting and blood-brain barrier permeability in subjects with chronic carotid artery stenosis. Int J Mol Sci 18: E1008. https://doi. org/10.3390/ijms18051008

Szarmach A, Kaszubowski M, Sabisz A, Frydrychowski AF, Halena G, Piskunowicz M, Dzierzanowski J, Studniarek M, Szurowska E, Winklewski PJ (2018) Regional resting state perfusion variability and delayed cerebrovascular uniform reactivity in subjects with chronic carotid artery stenosis. Acta Biochim Pol 65: 151-162. https://doi. org/10.18388/abp.2018_2581

Taheri S, Gasparovic C, Huisa BN, Adair JC, Edmonds E, Prestopnik J, Grossetete M, Shah NJ, Wills J, Qualls C, Rosenberg GA (2011) Blood-brain barrier permeability abnormalities in vascular cognitive impairment. Stroke 42: 2158-2163. https://doi.org/10.1161/ STROKEAHA.110.611731

Tavares A, Caldas JG, Castro CC, Puglia P Jr, Frudit ME, Barbosa LA (2010) Changes in perfusion-weighted magnetic resonance imaging after carotid angioplasty with stent. Interv Neuroradiol 16: 161-169. https://doi.org/10.1177/159101991001600207

Topakian R, Barrick T, Howe F, Markus H (2010) Blood-brain barrier permeability is increased in normal-appearing white matter in patients with lacunar stroke and leucoaraiosis. I Neurol Neurosurg Psychiatry 81: 192-197. https://doi.org/10.1136/jnnp.2009.172072

Trojanowska A, Drop A, Jargiello T, Wojczal J, Szczerbo-Trojanowska M (2006) Changes in cerebral hemodynamics after carotid stenting: evaluation with CT perfusion studies. J Neuroradiol 33: 169-174

Tong E, Wintermark M (2014) CTA-enhanced perfusion CT: An original method to perform ultra-low-dose CTA-enhanced perfusion CT. Neuroradiology 56: 955-964. https://doi.org/10.1136/ jnnp.2009.172072

van Sloten TT, Protogerou AD, Henry RM, Schram MT, Launer LJ, Stehouwer CD (2015) Association between arterial stiffness, cerebral small vessel disease and cognitive impairment: A systematic review and meta-analysis. Neurosci Biobehav Rev 53: 121-130. https:// doi.org/10.1016/i.neubiorev.2015.03.011

Waaijer A, van Leeuwen MS, van Osch MJ, van der Worp BH, Moll FL, Lo RT, Mali WP, Prokop M (2007) Changes in cerebral perfusion after revascularization of symptomatic carotid artery stenosis: CT measurement. Radiology 245: 541-548. https://doi.org/10.1148/ radiol.2451061493

Wardlaw JM, Doubal F, Armitage P, Chappell F, Carpenter T, Muñoz Maniega S, Farrall A, Sudlow C, Dennis M, Dhillon B (2009) Lacunar stroke is associated with diffuse blood-brain barrier dysfunction. Ann Neurol 65: 194-202. https://doi.org/10.1002/ana.21549

Wardlaw JM, Allerhand M, Eadie E, Thomas A, Corley J, Pattie A, Taylor A, Shenkin SD, Cox S, Gow A, Starr JM, Deary IJ (2017) Carotid disease at age 73 and cognitive change from age 70 to 76 years: A longitudinal cohort study. J Cereb Blood Flow Metab 37: 3042-3052. https://doi.org/10.1177/0271678X16683693

WHO MONICA Project Principal Investigators (1988) The World Health Organization MONICA Project (monitoring trends and determinants in cardiovascular disease): a major international collaboration. J Clin Epidemiol 41: 105-114

Wilkinson ID, Griffiths PD, Hoggard N, Cleveland TJ, Gaines PA, Macdonald S, McKevitt F, Venables GS (2003) Short-term changes in cerebral microhemodynamics after carotid stenting. AJNR Am J Neuroradiol 24: 1501-1507

Yang J, d'Esterre C, Ceruti S, Roversi G, Saletti A, Fainardi E, Lee TY (2015) Temporal changes in blood-brain barrier permeability and cerebral perfusion in lacunar/subcortical ischemic stroke. BMC Neurol 15: 214. https://doi.org/10.1186/s12883-015-0468-0

Yang Y, Rosenberg GA (2011) Blood-brain barrier breakdown in acute and chronic cerebrovascular disease. Stroke 42: 3323-3328. https:// doi.org/10.1161/STROKEAHA.110.608257 